\section{LOS TRABAJOS DE LA CIENCIA*}

\author{
Eduardo Sabrovsky Jauneau \\ Director, Instituto de Humanidades, \\ Universidad Diego Portales, Santiago de Chile \\ eduardo.sabrovsky@udp.cl
}

\title{
THE SCIENCE WORKS
}

\begin{abstract}
ABSTRACT: This paper has the purpose of showing the identity between science and technology from within scientific language. The traditional philosophical argument in favour of this identity is briefly examined, through the work of Heidegger. Then, following Henri Atlan ("Ordres et Significations", 1979. Le crystal et la fumée. Essai sur l'organisation du vivant. Paris: Éd. Du Seuil) the scientific definitions of order and disorder are reviewed; then Boltzmann's statistical formulation of the Second Law of Thermodynamics is discussed, to show that such a law could only appear in the context of Modernity and the Industrial Revolution. In fact, the concept of "mechanical work" would be the "missing link" assimilating science to techno-science, to technology. The paper also discusses the consequences of such an assimilation, and the resistance with which it is usually received by the scientific community. This resistance arises from the loss of the unconditional character of scientific truth. The concept of the "unconditional", its genealogy and ethic relevance within Modern philosophical thought, from Spinosa to Kant and Wittgenstein, are discussed. Finally, Emmanuel Lévinas' Ethics is introduced: for Lévinas, in fact, the recovery of the unconditional character of the ethical (and also, of cognitive truth) requires that the dialogic character of all kind of statements be taken into account.
\end{abstract}

KEY WORDS: Science, Technology, techno-science, 2nd Law of Thermodynamics, Atlan, Heidegger, Lévinas, unconditional, ethics.

En enero de 2005, con ocasión de la Escuela de Sistemas Complejos que por vez tercera organizó el Instituto de Sistemas Complejos de Valparaíso, Chile, nos visitó, su tercera vez también en Chile, el destacadísimo biólogo-matemático y filósofo de origen judío-francés Henri Atlan. Atlan es una de las figuras indiscutidas en este tema, el de la complejidad, tema que en su virtuosa vaguedad (todos los términos son vagos, ha dicho Wittgenstein: el de "complejidad", simplemente, no oculta su carácter difuso, inagotable) permite que, una vez más, como ha ocurrido con otros remezones experimentados por el edificio de las ciencias "exactas" en los últimos cien o más años, se produzca un cruce apasionante entre ciencias que se ven forzadas a volver sobre sus fundamentos ${ }^{1}$ y la reflexión filosófica.
RESUMEN: Esta comunicación pretende mostrar la identidad ciencia/técnica desde el interior del lenguaje tecnocientífico. Se revisa brevemente la argumentación filosófica tradicional al respecto, cuyo exponente paradigmático es Heidegger. Luego, siguiendo a Henri Atlan ("Ordres et Significations", Le cristal et la fumée. Essai sur l'organisation du vivant, Éd. Du Seuil, Paris, 1979) se analiza la definición científica de orden y desorden; enseguida se discute la formulación estadistica de Boltzmann de la 2. ${ }^{\text {a }}$ Ley de la Termodinámica, hasta mostrar que tal ley sólo pudo surgir en el contexto de la Modernidad y la Revolución Industrial; de hecho, en el concepto de "trabajo" se encontraría el "eslabón perdido" que permitiría asimilar la ciencia a la tecnociencia, a la tecnología. La comunicación discute también las consecuencias de esta identidad y las resistencias que despierta, derivadas de la pérdida del carácter incondicional de la verdad científica. Se discute el concepto de "incondicionalidad", su genealogía y relevancia éticas al interior del pensamiento filosófico moderno, desde Kant hasta Wittgenstein, y su negación en Spinoza. Finalmente, se introduce el pensamiento de Emmanuel Lévinas, para quien el restablecimiento de la incondicionalidad de lo ético (también de la verdad cognitiva) requiere más bien tomar en consideración el carácter dialógico de todo enunciado.

PALABRAS CLAVE: Ciencia, técnica, tecnología, tecnociencia, 2. Ley de la Termodinámica, Atlan, Heidegger, Lévinas, incondicionalidad, ética.

En lo que sigue, intentaré desarrollar de manera sistemática el tema sobre el cual me tocó exponer en esta Escuela de Sistemas Complejos: las relaciones entre ciencia y técnica. Mi postura, que pretendía ser provocadora, y en alguna manera lo fue (también podría ser, a estas alturas, banal) afirma, en principio, que ambas disciplinas son idénticas, lo que autorizaría a hablar más bien de "tecnociencia", en vez de tratar a ambas por separado. Y mi pretensión en esa exposición fue fundamentar esta afirmación, no en el discurso filosófico ya tradicional al respecto (por ejemplo, el que podría extraerse de ciertos escritos de Heidegger, y que describiré de modo somero más adelante), sino en un texto del propio Henri Atlan quien, por desgracia, había ya partido y no pudo escuchar y discutir mis planteamientos, 
escrito explícitamente, por cierto, a propósito de otro tema (su título, de hecho, es "Ordres et Significations", contenido en un libro, notable ya desde su título: Entre le Cristal et la Fumée), pero del cual se puede extraer, es mi pretensión, un argumento desde el interior mismo de la ciencia -y no desde la tradición filosófica que siempre, con o sin justicia, puede ser descartada por ser de alguna manera "exterior" a aquélla- a favor de la identidad entre ciencia y técnica ya afirmada. Este argumento gira, en última instancia, sobre el significado de la nociones científicas de orden y desorden, y de la de trabajo, muy cercana a la de energía.

Conviene empezar, en todo caso, por resumir la posición filosófica "tradicional", tal como se encuentra, ya lo hemos dicho, en Heidegger. Esta postura de Heidegger (a cuyo pensamiento, considerado globalmente, tiendo en todo caso a no adherir), fue planteada ya en Ser y Tiempo, y posteriormente desarrollada en una notable conferencia "La Era de la Imagen del Mundo" ("Die Zeit des Weltbildes"), pronunciada el 9 de junio de 1938 en Freiburg im Breisgau. Para Heidegger ${ }^{2}$, la técnica moderna (o la tecnología, tal como también diremos) no es, como aparece ante el sentido común, "ciencia aplicada". Más bien, la "imagen del mundo" que la Modernidad, y particularmente su ala cartesiano-científica proyecta es ya, desde un principio, tecnológica ${ }^{3}$. Uno de los argumentos que Heidegger ofrece, y que me parece el más adecuado para ser resumido, parte poniendo atención a la raíz griega de nuestra palabra "matemática", que para nosotros supone, de una u otra manera, un enfoque numérico, cuantitativo, ante los fenómenos. Pero Heidegger nos aclara que esta acepción corriente es más bien derivada, secundaria, no primordial.

La física moderna, escribe, se llama matemática porque aplica una matemática muy determinada en un sentido eminente. Pero sólo puede proceder de esta manera, matemáticamente, porque en un sentido más profundo ya es matemática. Ta mathemata significa para los griegos aquello que el hombre ya conoce por adelantado cuando contempla lo ente o entra en trato con las cosas: el carácter de cuerpo de los cuerpos, lo que las plantas tienen de planta, lo animal de los animales, lo humano de los seres humanos.

En otras palabras, "matemático" es en su origen, lo que, paradójicamente (pero atención: no tanto), conocemos antes de "conocer" en un sentido especializado. Antes de "conocer" conocemos de hecho el lenguaje y las prácticas, al interior de los cuales hemos sido socializados: sabemos (ésta es la esencia del apriorismo kantiano) del espacio, del tiempo, de "categorías" como la causalidad, que no han sido extraídas de nuestra experiencia individual, sino que constituyen el prisma, culturalmente determinado, bajo el cual nos aproximamos a lo real. Volviendo al argumento de Heidegger, lo matemático no es intrínsecamente numérico: lo numérico, en cambio, sí es esencialmente matemático, porque los números, los entes matemáticos en general, pueden ser considerados como el prototipo de aquello que conocemos antes de "conocer". Encerrados en una celda totalmente aislada del exterior, sin ningún input empírico, aún así, dice el razonamiento heideggeriano (también el kantiano), igual podríamos, si la duración de nuestra vida y la potencia de nuestras neuronas lo permitieran, construir toda la matemática. Dice Heidegger:

Cuando vemos tres manzanas sobre la mesa nos damos cuenta de que son tres. Pero es que ya conocemos el número tres, la triplicidad. Esto quiere decir que el número es algo matemático. Es precisamente porque los números representan del modo más imperioso eso que es siempre ya conocido y por lo tanto son lo más conocido de las matemáticas, por lo que el nombre de matemáticas quedó reservado para todo lo tocante a los números.

Hasta aquí Heidegger. Su argumento es fuerte, sin embargo hay quienes no se convencen, o no se dejan convencer por él. $Y$ hay una motivación poderosa y respetable para esta denegación (por ejemplo, de parte un segmento de la comunidad científica), puesto que, en esta perspectiva, las verdades de la ciencia dejan de ser incondicionales, "puras", y pasan de una u otra manera a ser meras verdades instrumentales, susceptibles de ser condicionadas, por ejemplo, por los intereses económicos, políticos, sociales, que se mueven tras la tecnología, y menos evidentemente, al menos en ciertos contextos, tras la ciencia. El científico encerrado en su gabinete, o sentado pensando en su jardín, oyendo a Bach y transportado al mundo platónico de las ideas, puede legítimamente plantearse: ¿qué tiene que ver la tecnología -i.e. la televisión, la industria cultural o armamentista- con lo que yo hago ${ }^{4}$. $Y$ es verdad que ello responde a su experiencia inmediata. Pero de la misma manera, la calma absoluta es la experiencia inmediata de quien está instalado en el ojo de un huracán. Ése es precisamente el planteamiento de Heidegger, y el que, aproximándonos más al lenguaje mismo de la ciencia, 
queremos desarrollar: respecto al turbulento mundo de la tecnología (en su relación, por ejemplo, con la cultura de masas y los negocios), la ciencia constituiría, ni más ni menos, el ojo del huracán.

Digamos que el tema de la incondicionalidad (de la verdad, en este caso) no es sólo preocupación de la ciencia. Lo es también de la ética, de la estética, que no querrian verse reducidas a la expresión de intereses (así, la ética no quisiera ser mera palabrería que enmascarase intereses económicos o de poder; de la misma manera, un artista quisiera que su obra se diferenciase de un simple objeto de uso -decorativo, por ejemplo- o de una mera mercancía). El fenómeno estético, en condiciones modernas o posmodernas, da igual (la Posmodernidad no es sino la Modernidad autorreflexiva, conciente de sí misma) tiende a restablecer efímeramente sus pretensiones de incondicionalidad mediante lo que en otro lugar hemos Ilamado "el sacrificio infinito": la permanente puesta en escena de su propia imposibilidad 5 . Y en cuanto a la ética, es parte de la discusión contemporánea (al final volveremos sobre este punto) la manera como sería posible, sin ingenuidad, sostener alguna pretensión de incondicionalidad ética ${ }^{6}$, al interior de una cultura, la nuestra, que ya ha hecho colectivamente el aprendizaje de que todo se reduciría a construcciones, manipulaciones e intereses.

Digamos, en síntesis, que es legítima la objeción a la identidad entre ciencia y técnica en la medida en que tras ella se deja ver una preocupación por la incondicionalidad. La respuesta a esta objeción podría consistir, o bien en establecer que hay lo incondicional, mas no le correspondería a la ciencia cautelarlo, sino más bien a la ética o la estética; o bien, replantear, sin abandonarlo, todo el tema de la incondicionalidad. Abordaremos estas alternativas al final de este texto.

Para cumplir con lo ofrecido (mostrar la identidad entre ciencia y técnica desde el interior del lenguaje tecnocientífico) nuestra estrategia será entrar, siguiendo a Atlan, a la discusión sobre la definición científica del orden y el desorden; luego, discutiendo con él la formulación estadística

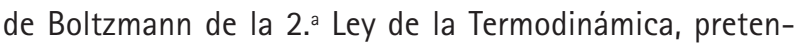
demos mostrar que tal ley sólo pudo surgir en el contexto de la Modernidad y la Revolución Industrial; finalmente, pretendemos sugerir que en el concepto de "trabajo" se encontraría algo así como el eslabón perdido que permite asimilar la ciencia a la tecnociencia, a la tecnología.

Partiremos con una cita más o menos larga de Atlan quien, al inicio del capítulo ya mencionado de Entre le cristal et la fumée ("Ordres et significations") retoma a su vez un ejemplo propuesto alguna vez por Bateson:

Es conocida la historia de la oficina y de las estanterías repletas de libros y documentos. Éstos están en apariencia apilados de cualquier forma. Sin embargo, su propietario sabe perfectamente encontrar si lo requiere cualquier documento que busca. Al contrario, si por desgracia a alguien se le ocurre "poner orden", se volverá quizás incapaz de encontrar allí lo que sea. Es evidente en este caso que e desorden aparente era un orden, y viceversa. Se trata aqu de documentos en relación con su usuario. El desorden aparente escondía un orden determinado por el conocimiento de cada documento y de su significado utilitario posible. ¿Pero en qué consistía la apariencia de desorden de este orden? En que, para un segundo observador, que quiere "poner orden" los documentos ya no tienen, individualmente, la misma significación. En el límite, no tienen ninguna más que aquella ligada a su forma geométrica y al lugar que podrian ocupar en la oficina y los estantes de manera de coincidir, en su conjunto, con una cierta idea a priori, un pattern, considerado como globalmente ordenado. Se observa entonces que la oposición entre orden y apariencia de orden proviene de que los documentos sean considerados globalmente con su significación, o lo sean globalmente con una significación individual diferente (determinada, por ejemplo, por su tamaño, su color o cualquier otro principio de ubicación aplicado desde el exterior y sin el consentimiento del usuario), o incluso sin significación en absoluto (p. 277).

En otras palabras, lo que Bateson y Atlan están ejemplificando es la idea de que enunciados que contienen la palabra "orden" o "desorden" no son del mismo tipo de los que enuncian propiedades objetivas de algún objeto (por ejemplo, "esta mesa es de madera y metal"). En este último caso, se puede suponer que un observador cualquiera (supuesto un cierto conocimiento, culturalmente dado, de los muebles y los materiales) concordará con este enunciado, el cual en este sentido pasa a ser "independiente del observador". En el caso del orden o el desorden, en cambio, no es posible "descontar" al observador: lo que el enunciado enuncia no es una propiedad objetiva sino más 
bien la existencia (orden), o inexistencia (desorden) de una relación entre el objeto y un observador, en este caso el usuario: de una conmensurabilidad, podríamos decir, entre las representaciones del usuario y lo real ${ }^{8}$. Podríamos decir que, a diferencia de los enunciados que se refieren a propiedades objetivas, los que se refieren al orden (y al desorden) son enunciados de segundo grado: no se refieren directamente al objeto, sino a la relación posible entre un objeto y su usuario, su observador.

Frente a esta "relativización" de los conceptos de orden y desorden se erige, al parecer, la objetividad de la medición del orden en termodinámica, dada por su formulación estadística alcanzada por Boltzmann:

$$
\begin{gathered}
S=k \sum_{i=1}^{\Omega} P_{i} \ln P_{i} \\
\sum_{i=1}^{\Omega} P_{i}=1
\end{gathered}
$$

donde S es la llamada "entropía", k es una constante universal (Ilamada de Boltzmann, igual a 3,3 × 10-24 calorías/ grado, y las probabilidades $p_{i}$ corresponden a las probablidades de encontrar un fragmento de materia (un gas, por ejemplo) en cada uno de sus $\Omega$ estados posibles.

Originalmente, la entropía era una magnitud macroscópica, establecida por científicos y constructores de máquinas (Carnot, Clausius, Kelvin) de la primera revolución industrial (máquinas que transforman energía calórica en energía cinética y en "trabajo" mecánico), y que daba cuenta del hecho, observable, en virtud del cual toda máquina de este tipo experimenta pérdidas, debidas a un fenómeno que la física de Galileo y Newton aún consideraba posible de ignorar (por tratarse de una magnitud causal muy pequeña, "despreciable" como se dice o decía en jerga científica $^{9}$ ), pero que ahora aparece como irreductible: el roce, la fricción. Así, por más eficiente que sea una máquina, es imposible que recupere sin pérdidas el calor invertido originalmente en la producción de movimiento (energía cinética): siempre hay roce, siempre una cantidad de calor que se pierde irreductiblemente. El mérito de Boltzmann consistió, primordialmente, en tender un puente entre la física clásica y esta ley que en un principio parecía meramente práctica, inductivo-observacional. Para tender tal puente debió, eso sí, incorporar a la física, de manera inherente, el cálculo y el modo de pensar estadístico, probabilístico, originalmente surgido en el estudio de las poblaciones humanas ${ }^{10}$; después de esta incorporación, la física clásica no fue jamás la misma, puesto que preguntas fundamentales, del tipo "¿juega Dios a los dados?" irrumpieron a su interior.

En su expresión microscópica o estadística, la 2. ${ }^{a}$ Ley de la Termodinámica, o Ley de Entropía, tiene en su base en el hecho de que, como dice Atlan, "la materia sólo se deja constreñir, dominar, hasta cierto punto" (p. 29). Ahora, en términos microscópicos y estadísticos (la estadística proporciona la herramienta que permite tratar con una enorme cantidad de interacciones aleatorias entre moléculas microscópicas, como ocurre en el caso clásico de un gas), esto significa, nuevamente en palabras de Atlan, lo siguiente:

Las transformaciones impuestas por la máquinas implican una orientación, un ordenamiento de la materia y de sus constituyentes (moléculas, átomos). La materia dejada a si misma ignora este orden impuesto por el constructor de máquinas. En particular, la principal fuente de energía natural, el calor (el del fuego y el sol) tiene por efecto agitar las moléculas de modo desordenado, es decir, aleatorio, en todas direcciones, sin que ninguna sea, incluso en promedio, estadísticamente, privilegiada. Para que haya movimiento, desplazamiento de materia, trabajo, es necesario que todas las moléculas del trozo de materia en cuestión se desplacen conjuntamente en la misma dirección.

Transformar el calor en trabajo implica que se introduce orden en el movimiento desordenado de las moléculas para dar con un movimiento orientado, tal que en promedio las moléculas se desplacen en una misma dirección. Esta transformación, impuesta desde el exterior, no puede ser total: una cierta porción de desorden molecular existirá siempre, lo cual se traducirá en calor no utilizable. Esto es lo que dice el segundo principio de la termodinámica, en su expresión estadística (p. 29).

Llama la atención de inmediato en estas citas la relación que tácitamente establecen entre la formulación del segundo principio de la termodinámica, y un factum histórico primordial: el advenimiento de la empresa planetaria de dominación de la materia, la Modernidad y la Revolución Industrial. Sólo ella, la empresa de dominación de la materia, puede constituir el contexto para una afirmación como 
la reproducida más arriba: "la materia sólo se deja constreñir, dominar, hasta cierto punto". Sólo en este contexto, en el cual el viejo orden inherente al Cosmos medieval ha sido sustituido por una "voluntad de orden"11, de afirmación humana en medio de un universo devenido caótico ${ }^{12}$, es posible pensar en máquinas que pretenden maximizar la transformación de energía calórica en trabajo mecánico, es decir, introducir "orden en el movimiento desordenado de las moléculas para dar con un movimiento orientado, tal que en promedio las moléculas se desplacen en una misma dirección". Desde este punto de vista, el segundo principio de la termodinámica dejaría de ser incondicionalmente objetivo, lo cual no significa que haya que temer que se transforme en algo meramente subjetivo: por sobre lo objetivo y lo subjetivo (esto a menudo los científicos lo ignoran) está lo a priori. Es decir, el prisma a través del cual un observador colectivo (la sociedad, la cultura de la Modernidad en este caso), formado en cuanto tal por procesos de socialización al interior de prácticas, formas de vida y lenguajes, observa la realidad. En el caso de la Modernidad, este prisma supone como un dato indiscutible, como "infundado fundamento"13, la magna empresa del "desencantamiento" de la naturaleza -la Entzauberung (desmagificación) de Max Weber-y el advenimiento de sus consecuencias: la racionalidad instrumental y el mercado, la libertad del individuo ilustrado, emancipado de la tutela de la vieja institución eclesiástico estatal. La supuesta incondicional objetividad de la segunda ley de la termodinámica (es decir, de la medida del orden) resulta, siguiendo a Atlan, ser el producto de una mirada "prismática" sobre la realidad: una mirada bajo el prisma socio-cultural de la Modernidad, y sólo bajo él.

En algún momento de su escrito, Atlan parece querer distinguir la concepción de orden dependiente del observador de la concepción supuestamente objetiva (porque expresada matemáticamente) del orden en física. Dice Atlan:

\footnotetext{
Así, la definición del orden y del desorden en la Naturaleza presenta diferencias evidentes con aquella que estaba implícita en el ejemplo de la oficina y su ordenamiento. El primer rasgo que los distingue es que aquí la definición parece objetiva, medida mediante una magnitud física, la entropía. En el ejemplo de la oficina por el contrario, el carácter ordenado dependía de la significación posible del orden, diferente para usuarios diferentes (p. 32).
}

No obstante, en el párrafo siguiente se pone en evidencia que esta vuelta a la distinción fuerte entre el orden objetivo y el dependiente de un observador no es más que un recurso retórico ("la definición parece objetiva") para enfatizar precisamente lo contrario. Así, inmediatamente, Atlan agrega.

Y sin embargo la entropía, magnitud física, no se define más que en relación a las posibilidades de observación y de medida como lo muestra el ejemplo de la entropía de la mezcla de dos gases diferentes. La formación espontánea de una mezcla homogénea de dos gases se acompaña evidentemente por un aumento de la entropía que eventualmente es susceptible de ser medida. Ahora bien, este fenómeno se concibe diferentemente si se lo observa antes o después del descubrimiento de la radiactividad. Si se utiliza moléculas radiactivas de un mismo gas, ya no es el mismo gas, y hay una entropía de la mezcla. i Lo que quiere decir que para un mismo sistema de dos recipientes de un mismo gas, uno radiactivo, el otro no, que se los deja mezclar, no existía entropía antes del descubrimiento de la radiactividad, y si existe después de tal descubrimiento! (p. 32, las itálicas son nuestras).

Lo que mueve a Atlan a la exclamación (lo que quería enfatizar mediante el mencionado efecto retórico) es el hecho que hay dos mediciones para la entropía de la mezcla de un gas, ambas correctas, dependiendo de un factor que no podría sino calificarse de tecnocientífico (y que legitima el uso de este término): el descubrimiento de la radiactividad. Sólo ella, en el ejemplo de Atlan, permite distinguir las moléculas de un mismo gas dispuestas en contenedores diferentes y conectados: esta distinción, producto de nuevas "posibilidades de observación y de medida", es la fuente de aumento de entropía, y fuente también de energía y de trabajo mecánico.

Recordemos que le energía se define como la capacidad para realizar trabajo. Se da entonces, la paradoja (pero de nuevo, nunca tanto), de que una distinción en principio puramente observacional, pero producto de un complejo desarrollo teórico-empírico de las ciencias naturales, inseparable del desarrollo general de las fuerzas productivas (el descubrimiento, en este caso, de la radioactividad) permite obtener energía y trabajo donde antes no lo había.

Podemos entonces definir el rol tecnológico, tecnocientífico de la ciencia (y explicar, como propusimos más arriba, la

ARBOR CLXXXIV 732 julio-agosto [2008] 759-769 ISSN: 0210-1963

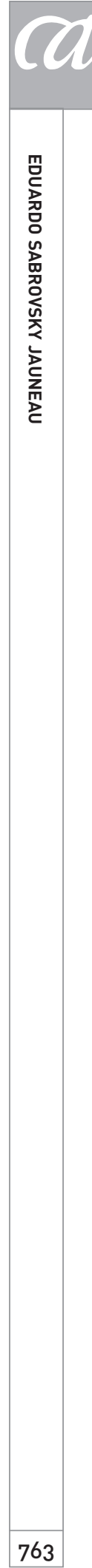


calma aparente en que transcurre, al parecer relacionada sólo distantemente con la vorágine tecnológica, no como la calma del margen, sino la del mismo centro del vortex) a partir de la tarea fundamental de la ciencia: introducir nuevas distinciones. Son estas, curiosamente, las que permiten extraer nuevas energías y fuentes de trabajo de la naturaleza. Una labor aparentemente de tipo puramente teórico, contemplativo (theorein en griego está relacionado con la visión, la contemplación), pero inserta, claro está, a través de la división del trabajo, en el complejo de las fuerzas productivas, viene a ser la fuente principal de energía y trabajo requeridos por el modo de producción industrial o postindustrial ${ }^{14}$, para el cual la ciencia (y no como mera "ciencia aplicada", por lo que ya hemos argumentado), resulta central.

Con esta conclusión, la tarea propuesta al inicio de esta comunicación -reducir (o ampliar) la ciencia a "tecnociencia", a tecnología- está en lo fundamental cumplida. Resta ahora hacerme cargo de las interrogantes filosóficas que de tal conclusión se siguen, tal como también lo ofrecí al inicio del texto. En efecto, la identidad entre ciencia y técnica que, valiéndonos de la problemática científica del orden y el desorden, hemos establecido, tiene en principio por consecuencia el despojar a las verdades de la ciencia de todo carácter de incondicionalidad. Lo cual equivale a decir, como lo he aclarado también más arriba, que el saber científico como tal quedaría inmerso -por cierto, no de manera inmediata y burda- en las turbulentas aguas de la tecnología y el mercado.

Se hace importante también tratar esta cuestión (que, en su núcleo, es la de la no-incondicionalidad de la verdad) dado que, en una de sus conferencias en la Escuela de Sistemas Complejos de Valparaíso, el propio Atlan dedicó su charla a exponer, en relación a la biología, el pensamiento del filósofo Baruch Spinoza, a quien podría considerarse el exponente más elevado (junto a Nietzsche, quien reconocía la grandeza de Spinoza) de un monismo filosófico que excluye la concepción de toda esfera de incondicionalidad. En una conversación posterior a su conferencia, el propio Atlan me relató que su interés en Spinoza había surgido hace pocos años, después de advertir que muchas veces su pensamiento era calificado por sus lectores, auditores y críticos, como "spinozista". Y que al leer al filósofo judeoíbero-holandés, decidió asumir su hasta entonces ignorada deuda con él.
Para Atlan, haciendo explícita su afinidad con Spinoza en nuestro encuentro de Valparaíso, "la voluntad y el entendimiento son una y la misma cosa". No es difícil rastreaar en la Ética spinoziana afirmaciones del mismo tenor. Así, por ejemplo (Pars Quarta, "De Servitude Humana seu de Affectuum Viribus") en la Proposición XXII se dice: "No se puede concebir virtud alguna anterior al esfuerzo para conservarse ${ }^{15 " .}$ Y de aquí, líneas más adelante, Spinoza extrae el siguiente Corolario:

"El esfuerzo para conservarse es el primero y único origen de la virtud. Porque no se puede concebir (...) ningún otro principio anterior a éste, y sin él (...) no se puede concebir ninguna virtud"16.

Spinoza está haciendo un esfuerzo, y ello constituye el núcleo de su pensamiento, por alejarse del dualismo cartesiano que distingue ontológicamente entre res cogitans y res extensa, entre los seres humanos (y Dios), y la naturaleza. En oposición, diríamos que Spinoza naturaliza la razón humana, y particularmente la razón práctica, la ética: la virtud, el bien, no es sino una máscara de la autoconservación. En una nota más arriba hemos enunciado las incomodidades y paradojas que se siguen del pensamiento spinoziano: al no haber diferencia entre la ética y los intereses de autoconservación, no hay lugar desde el cual estos intereses puedan ser puestos en cuestión. Spinoza anticipa el utilitarismo y pragmatismo contemporáneos: si somos fieles a su punto de vista, serían imposibles (meros sinsentido) obras como El Malestar en la Cultura, de Sigmund Freud ( $y$, posiblemente, todo el psicoanálisis). Pues precisamente alli se intenta hacer un balance de los costos y beneficios de la cultura entendida como autoconservación, en un momento en el cual (las Guerras Mundiales, la Shoah) pareciera haber irrumpido, en el escenario de la historia, todo el dolor, la ruina y barbarie que, como una sombra, acompañaría a toda cultura ${ }^{17}$.

Desde el punto de vista spinoziano (que se vería reforzado, en principio, por la identidad entre ciencia y técnica, entre verdad e instrumentalidad, que más atrás, siguiendo a Atlan, hemos derivado), no tiene sentido plantearse, por ejemplo, "la postergación indefinida de la hora de la traición". ¿Cómo, y por qué, postergarla, si la voluntad carece de autonomía? Esta postergación, sin embargo, constituye, para Emmanuel Lévinas, pensador judeo-francés de la segunda mitad del siglo XX, la esencia de lo humano ("ínfima 
diferencia entre el ser humano y el no-ser humano") ${ }^{18}$. Volveremos brevemente sobre Lévinas al final de este texto.

Emmanuel Kant ha sido, seguramente, el más tenaz opositor al spinozismo en la era de la llustración. Si bien, en su Crítica de la Razon Pura Kant reconoce en la ciencia de Newton y Galileo un momento de incondicionalidad ${ }^{19}$, esta incondicionalidad podría todavía ser reabsorbida por el spinozismo, y considerada como una máscara de intereses cognitivos "heterónomos", es decir, impuestos desde afuera, en la terminología kantiana. Por eso, Kant se vuelve directamente hacia la ética. Su Fundamentación de la Metafísica de las Costumbres se inicia con esta "inocente" sentencia: "Ni en el mundo, ni en general fuera de él es posible pensar nada que pueda ser considerado bueno sin restricción, excepto una buena voluntad"20. Es decir, todo lo empírico es a-valórico: ningún bien que sea realmente un bien, y no una máscara de intereses mundanos, se podría hallar allí. Se suele criticar a Kant llevando al absurdo su posición (él mismo en ocasiones lo hace), puesto que, si el bien debe quedar incontaminado por la empiria, valdría más un filántropo avaro que un filántropo sin más, un amante de la humanidad, de buen corazón (puesto que, si es de buen corazón, podría obtener un goce empírico, heterónomo, de su acto filantrópico). La ética kantiana parece quedar así sustraída de toda relación con la realidad: reducida a una apelación a la santidad, al abandono de los intereses mundanos por parte del filósofo, y al paralelo abandono del mundo a la más cruda instrumentalidad. Ahora bien: distinta se presenta esta ética si entendemos que la elección que nos impone no se da entre un sujeto puro, incontaminado, versus un sujeto que ni siquiera llega ser tal, pues no es sino el juguete de la causalidad externa o interna (sus pasiones), sino entre un sujeto empírico y un sujeto moderno, desgarrado, permanentemente escindido entre el cumplimiento de su deber y sus intereses y pasiones ${ }^{21}$. 0, como lo decía ese kantiano que era Max Weber quien, refiriéndose a la actividad política, advertía el desgarro constitutivo de la Modernidad entre un "ética de la responsabilidad" (una ética del cálculo de las consecuencias de las acciones) y una "ética de las convicciones", o del corazón, cuyas demandas son incondicionales. El hombre político (¿no lo somos todos?) estaba, según Weber, permanentemente desgarrado entre estas dos lógicas ${ }^{22}$.

Aunque mucho se puede extraer de Kant aún hoy en día, el sentido común de la historia de la filosofía dice que las pretensiones de incondicionalidad de la ética kantiana quedaron pulverizadas por ese spinozista que fue Federico Nietzsche: para él (por ejemplo, en La Genealogía de la Moral) el sujeto autónomo, ético, kantiano, no es sino el resultado de una domesticación: la "crianza" de un animal capaz de hacer promesas, es decir, de postergar la satisfacción de sus intereses empíricos en pro de un interés superior. "El imperativo categórico [kantiano], dirá Nietzsche, huele a crueldad"; es el resultado, dirá Michel Foucault, su continuador en el siglo XX, de tecnologías sociales de vigilancia y castigo (Vigilar y Castigar), de las cuales formarian parte de manera eminente las ciencias sociales. Finalmente, la única defensa para un sujeto cuyo comportamiento pudiese quedar sustraído de las explicaciones empíricas consiste en transformarlo en un punto virtual. Así sucede en el primer Wittgenstein (el del Tractatus Lógico Philosophicus) donde el sujeto no desaparece, pero queda transformado en un límite del mundo: en un punto virtual, de dimensión cero ${ }^{23}$.

A lo largo de esta línea de razonamiento, se abandona, por así decirlo, a la ciencia en manos del spinozismo, con el objeto de salvar a la ética (y a la estética). Desde el punto de vista del discurso cognitivo, el ser humano no sería sino una marioneta, manejada tras bambalinas por alguna versión de la causalidad. El ser humano, en otras palabras, no hablaria: las circunstancias -físico-químicas, genéticas, sociológicas, económicas, psicológicas incluso- "hablarian" ventrílocuamente a través de él. El discurso de la ciencia -también el de la filosofía, en la cima de su moderna autoconciencia- dice "no hay verdad", "la verdad es que no hay verdad". A no ser que se distingan lenguajes y metalenguajes (lo cual es difícil, al interior del lenguaje natural), esto comporta una contradicción performativa (como la de quien dice "yo miento"). Asi parece culminar el discurso científico de la Modernidad (y buena parte del filosófico): en una declaración de afasia autocontradictoria.

"Civilización de afásicos", dice refiriéndose a esta conclusión Emmanuel Lévinas. No obstante, y con esto daremos término a esta comunicación, desde el punto de vista lévinasiano no es imprescindible tal sacrificio de los intereses cognitivos de la razón a favor de una muy problemática salvación de sus intereses éticos (de partida, la distinción neta entre estos intereses es problemática). Para Lévinas en su núcleo todos los discursos son éticos, en la medida 
en que el hablar (aunque sea para decir "yo no hablo") es siempre la respuesta a la interpelación de un Otro, el cual desde una posición de altura, o en todo caso asimétrica (asimetría que impide que se restablezca la equivalencia, la intercambiabilidad entre ambos) interpela a un Mismo inherentemente separado, irreductible incluso a una unidad genérica con su interlocutor. La incondicionalidad de lo ético se fundamenta precisamente en este carácter "dialógico" (pero se trata de un diálogo jamás simétrico), donde soy incondicionalmente interpelado a responder de mis dichos, incluso de mis dichos cognitivos y negativos, enfrentado cara a cara a mi interlocutor. Lo social, la dualidad y el pluralismo, en oposición al monismo de la razón spinozista, no es un accidente, sino la "curvatura misma del ser", ha dicho Lévinas. Y ha dicho también: "La objetividad no es lo que resta de un utensilio o de un alimento, separados del mundo donde se juega su ser. Ella se instala en un discurso, en un entre-tener que propone el mundo. Esta proposición se juega entre dos puntos que no constituyen sistema, cosmos, totalidad"24.

\section{NOTAS}

* Este trabajo ha sido elaborado en el contexto del proyecto de investigación Fondecyt (Fondo Nacional para la Ciencia y la Tecnología, República de Chile) N. 1030201, años 2003 a 2004, "Filosofía heideggeriana de la técnica, teoría del diseño y ciencia de lo artificial: elementos para una comprensión filosófica de la técnica en el mundo contemporáneo".

1 Fundamentos en los cuales, de manera indiscernible, se mezclan cuestiones de hecho y cuestiones de valor: basta para esto con echarle una mirada a la correspondencia entre Leibniz y Clarke, secretario de Newton, en los albores de la ciencia moderna: allí, por ejemplo, se parte discutiendo la manera de explicar científicamente el choque de dos bolas de billar; pocas líneas más adelante, y en perfecta continuidad argumentativa, se pasa a debatir la existencia de Dios, sus relaciones con el mundo humano, y las consecuencias éticas y políticas de cada una de las posibles posiciones.

2 Heidegger, aclarémoslo desde ya, no es un lego en lo que ciencia se refiere. Sus primeros estudios universitarios fueron precisamente en física.
3 En términos heideggerianos estrictos, pero que suelen confundir a los no iniciados, ya con esta sentencia bastaria: "proyectar" una "imagen del mundo" sería de por sí una actitud tecnológica.

4 ¿Qué tiene que ver de modo inherente, más allá de la mera "aplicación"? En última instancia, ésta es la pregunta que está respondiendo Einstein, con un "no" rotundo, cuando niega que Dios "juegue a los dados". Porque si Dios juega a los dados, habría una brecha entre nuestros conocimientos, que pasarian a ser intrinsecamente probabilísticos, y la verdad incondicional. $Y$ es a través de esta brecha, por ínfima que sea, por donde pueden infiltrarse los muy materiales condicionamientos e intereses mundanos. Con la mejor de las intenciones éticas, pero con no tan buen razonamiento filosófico, Einstein quiso disociar sus descubrimientos de asuntos tan nauseabundos como la invención de la bomba atómica. El problema, que trataremos un poco más adelante, es si acaso la incondicionalidad ética (del bien) requiere de la incondicionalidad de la verdad cognitiva, o si hay que plantear las cosas totalmente en otro terreno.
Recibido: 10 de enero de 2007 Aceptado: 29 de marzo de 2007 
5 Ver para esto: Eduardo Sabrovsky, De lo extraordinario. Nominalismo y Modernidad, UDP-Cuarto Propio, Santiago de Chile 2001. Mediante las ideas de "sacrificio infinito" y de "producción de lo extraordinario", pretendemos alli dar cuenta de la "extrañeza" inherente al arte contemporáneo.

6 Esto de la incondicionalidad ética parece un asunto de filósofos metafísicos y de su jerga. Sin embargo, no lo es. Lo incondicionado es lo opuesto a lo condicionado, a lo empírico, que para la Modernidad heredera del nominalismo de la Alta Edad Media y de la Reforma protestante, es de suyo valóricamente neutro. Éste es el contenido, por lo demás, del muy científico y moderno "postulado de objetividad", que prohibe que explicaciones finalistas de los fenómenos naturales sean consideradas científicas. Si no hay fines y valores que puedan ser "leídos" desde el Libro de la Naturaleza (para el Medioevo sí los había), entonces los valores sólo pueden quedar alojados en la esfera del sujeto moderno, que necesariamente ha de constituir una esfera sustraída de las explicaciones causales. Puesto que no se puede ser responsable por algo causalmente determinado, sea por una causalidad genética, física, económica, sociológica, físico-química, o cualquiera otra imaginable, sólo se puede atribuir responsabilidad si, de alguna manera, es posible -magna tarea- defender la existencia de una esfera sustraída de las explicaciones causales. En la charla de Valparaíso que aquí estoy sistematizando, alguien propuso dejar de lado esta ficción del sujeto responsable (ficción, pero ficción dotada de eficacia social: eso era el sujeto responsable, para Nietzsche) y simplemente asignar premios y castigos a las consecuencias observables de los actos. Es fácil mostrar las incomodidades y paradojas en la que caeria esta especie de conductismo ético o jurídico. Así, si mientras estoy mostrándole a un amigo la más reciente adquisición en mi colección de puñales exóticos, sufro un ligero síncope, caigo sobre él y lo mato, sería culpable de asesinato; no lo sería quien, mediante una bien diseñada red de contactos, mandase a asesinar a otro.

7 La cita corresponde a: Atlan, Henri, Le cristal et la fumée. Essai sur l'organisation du vivant, Éd. Du Seuil, Paris, 1979. En adelante, daremos sólo el número de página de esta edición. A no ser que se indique expresamente lo contrario, todas las traducciones incluidas en esta comunicación son mias.

8 La idea de la conmensurabilidad entre las representaciones y lo real puede ser proyectado al terreno de las representaciones colectivas. Así, para la cultura del Medioevo, la conmensurabilidad entre las representaciones humanas y lo real (el Kosmos griego, cristianizado) está garantizada por la creación de éste por parte de un Dios bueno, no un genio maligno y engañador como el que se le aparecerá con posterioridad a Descartes. Lo que este Dios garantiza es, en otras palabras, el orden del universo el cual, justamente por ser un orden, es susceptible de ser inteligido por el ser humano. Por cierto, no por todos los seres humanos, sino por aquellos que unen al desarrollo de la razón el ser los depositarios únicos de una revelación: en otras palabras, por la institución eclesiástica y política medieval, que se atribuye la capacidad de descifrar el orden del universo y de traducirlo en términos de normas ético-políticas, en términos de un orden social, que pasa a ser obligatorio para todos. En esta operación de desciframiento y traducción se apoyan la hegemonía, la legitimidad del poder de dicha institución en la sociedad medieval.

9 La novedad de la teoría del caos consiste en que no hay proporcionalidad entre causas y efectos: pequeñas causas pueden producir, transcurrido un tiempo suficiente, enormes efectos. De aquí en adelante, ninguna magnitud física es a priori "despreciable".

10 Para este origen de la probabilidad y la estadística en las ciencias humanas y sociales, ver los libros del filósofo canadiense lan Hacking The Emergence of Probability: A Philosophical Study of Early Ideas About Probability, Induction and Statistical Inference, Cambridge University Press, 1975, y The Taming of Chance (Ideas in Context), Cambridge University Press, 1990.

11 Esta sustitución, como bien lo ha mostrado nuevamente Heidegger tiene su expresión filosófica en la transformación, de Descartes en adelante, de la filosofía de la Modernidad en "filosofía del sujeto", de un sujeto caracterizado esencialmente por su voluntad, hasta culminar en la ontología de la "voluntad de poder" de Nietzsche. Heidegger llama la atención sobre el significado originario de la palabra sujeto: sub-jectum, es decir lo que subyace -fundamentopalabra latina que traduce el término griego hypokeimenon. El sujeto no es originariamente un ser humano, sino un fundamento. La Modernidad sería aquel evento historial en virtud del cual la mente y sus representaciones pasan a acupar el lugar primordial del fundamento. 
12 Ver para esto la obra del filósofo alemán Hans Blumenberg, en particular su libro La legitimidad de la era moderna (Die Legitimität der Nuezeit, Francfurt, M., 1966).

13 Infundado, esto es, desde un punto de vista lógico.

14 Si se piensa más a fondo esta relación entre contemplación teórica y trabajo, quedan de lado todas las bizantinas discusiones que pretenden distinguir entre trabajo manual e intelectual. La principal fuente de trabajo tecnológico, y de trabajo sin más, es la habilidad humana para hacer distinciones. Habría que inscribir esta afirmación en la historia del concepto de trabajo, lo cual desborda el alcance de esta comunicación.

15 El "conservarse" es el famoso "connatus essendi" de Spinoza: todas las cosas (incluyendo al ser humano, que desde ello, y fundamentalmente por ello, no se distingue de la naturaleza) perseveran en su ser.

16 Baruch Spinoza, Ética-Tratado Lógico-Político, trad. Francisco Larroyo, Ed. Porrúa, México 1999, pp. 127128.

17 "No hay documento de la civilización que no sea a la vez un documento de la barbarie". Esta frase está contenida en la VII de las tesis sobre el concepto de historia (se las conoce como "Tesis sobre Filosofía de la Historia") que Walter Benjamín, pensador judeoalemán que se suicidó en 1940 al no poder huir del nazismo, dejó escritas antes de su muerte. Es de suyo evidente que el spinozismo transforma en absurdas proposiciones como éstas, o como las de Freud.

18 Emmanuel Lévinas, Totalité et Infini, Kluwer Academic, 1992, p. 23. Para una apreciación de Lévinas respecto a Spinoza, en la cual, a partir de una lectura del Tratado Ético-Políti- co, se pone en cuestión el monismo que parece desprenderse de textos spinozianos como la Ética, ver el ensayo "Avez vous relu Baruch?" incluido en Difficile Liberte. Essais sur le judaisme. Albin Michel, Paris, 1963. Alli Lévinas observa que para el Spinoza del Tratado, la validez de las Escrituras judeo-cristianas es de otro tipo (ético), distinta de la validez (verdad) cognitiva de la filosofía y la ciencia.

19 De normatividad, podriamos también decir, en la medida en que la pretensión de la ciencia de Newton y Galileo no es meramente inductiva: pretende decir, no como las cosas empíricamente son, sino como "deberían ser": incluso en las galaxias más inalcanzables (de las cuales se carece de toda experiencia) debe ser válida la ley de inercia. La problemática de lo incondicional puede ser dicha en términos de la diferencia entre "hechos" y "normas". De los hechos, sólo puede haber generalización inductiva, empírica, las normas, en cambio, aspiran a ser universales. Esto queda recogido en el llamado "lema de los empiristas": "de un ser no se sigue un debe" (Hume). Kant, en última instancia, es fiel a esta distinción.

20 Immanuel Kant, Fundamentación de la Metafísica de las Costumbres, ed. Luis Martínez de Velasco, Espasa Calpe, Madrid, 1998, p. 53.

21 Ver para esto: Allenka Zupancic, The Ethics of the Real. Kant and Lacan, Verso, Londres, 2000.

22 Ver para esto: Max Weber, "La política como profesión", en La ciencia como Profesión - La política como Profesión, trad. Joaquín Abellán Garcia, Austral, Madrid, 1992.

23 Tractatus Lógico-Philosophicus, 5.632: "El sujeto no pertenece al mundo, sino que es un límite del mundo". En el eje spinozismo-antispinozismo, se podría considerar que la obra primera de Wittgenstein (el Tractatus) pertenece a la segunda tendencia; su obra póstuma (las Investigaciones Filosóficas, para las cuales toda expresión del lenguaje está asociada a un uso, a un determinado "juego de lenguaje" y a las prácticas sociales que lo constituyen), a la primera.

24 Emmanuel Lévinas, Totalité et Infini, Essai sur l'exteriorité, p. 97. Para los iniciados, esta afirmación va claramente dirigida contra Heidegger, quien en Ser y Tiempo (Sección I, Capítulo III, "La mundaneidad del mundo") afirma que la objetividad cartesiana sería una forma deficitaria de entender el mundo, incapaz de dar cuenta de la modalidad primordial de la instrumentalidad, en virtud de las cuales las cosas, antes de ser objetos, son "equipamiento" (Zeuge) para un usuario. Ésta es la parte de Heidegger (de cuyas consecuencias pragmáticas Heidegger se intenta desprender en la Sección II de Sery Tiempo) que ha sido popularizada en Chile y los EE.UU. de Norteamérica por Fernando Flores y sus seminarios de emprendimiento.

\section{REFERENCIAS BIBLIOGRÁFICAS}

Atlan, Henri (1979): Le cristal et la fumée. Essai sur l'organisation du vivant, $\mathrm{Pa}$ ris, Éd. Du Seuil.

Benjamin, Walter (1955): "Geschichtsphilosophische Thesen", Schriften, Franfurt, M. Suhrkamp.

Blumenberg. Hans (1966): Die Legitimität der Neuezeit, Franfurt, M. Suhrkamp.

Foucaut, Michel (1975): Surveiller et Punir, Paris, Gallimard. 
Hacking, lan (1975): The Emergence of Probability: a Philosophical Study of Early Ideas About Probability, Induction and Statistical Inference, Cambridge, Cambridge University Press.

Hacking, Ian (1990): The Taming of Chance (Ideas in Context), Cambridge, Cambridge University Press.

Heidegger, Martin (1927): Sein und Zeit. Jahrbuch für Philosopie und phänomenologische Forschung, vol. VII, pp. 1-438, Halle.
Heidegger, Martin, 1938 (1977): The Question Concerning Technology and Other Essays, William Lovitt (trans.), New York, Harper Torchbooks.

Kant, Immanuel: Fundamentación de la Metafísica de las Costumbres.

Lévinas, Emmanuel (1963): Difficile Liberté. Essais sur le judaisme, Paris, Albin Michel.

Lévinas, Emmanuel (1992): Totalité et Infini, Paris, Kluwer Academic.

Nietzsche, Friedrich: Zur Genealogie der Moral. Eine Streitschrift.
Sabrovsky, Eduardo (2001): De lo Extraordinario, Nominalismo y Modernidad, Santiago de Chile, UDP-Cuarto Propio. Spinosa, Baruch: Ethica Ordine Geometrico Demonstrata.

Spinosa, Baruch: Tractatus Theologico-Politicus.

Wittgenstein, Ludwig (1922): Tractatus Lógico-Philosophicus C. K. Odgen (trans.), London, Routledge.

Zupancic, Alenka (2000): The Ethics of the Real. Kant and Lacan, London, Verso. 